\title{
Submucous myomas: diagnosis and therapy
}

\author{
Andreas L. Thurkow • Co'tje F. Admiraal • \\ Mark H. Emanuel • Paul J. M. van Kesteren • \\ Sebastiaan Veersema
}

Received: 12 June 2007 / Accepted: 10 July 2007 /Published online: 19 December 2007

(C) Springer-Verlag 2007

\begin{abstract}
In this review problems concerning diagnosis and therapy of submucous myomas are discussed. In abnormal blood loss, especially during menstrual periods, it is probable that the submucous locations of fibroids have the strongest relationship with the symptoms. Both in diagnostic and therapeutic possibilities, in the past decennium, a wide range of fine tuning has been developed that has changed dramatically the optimal management of submucous myomas and, therefore, of bleeding abnormalities during premenopause. Over-treatment can thus be prevented: for instance, hysterectomy in menorrhagia caused by a small pedunculated submucous fibroid. New modalities of minimally invasive treatment, however, have specific intrinsic problems that justify the development of protocols for these techniques. For the diagnosis of submucous myoma, and preceding operative treatment, intrauterine diagnosis through ultrasound or hysteroscopic imaging is mandatory. Hysteroscopic treatment of submucous myomas is the method of preference, unless the abnormality is too large or too numerous. Various practical aspects of treatment are discussed. Surgery for abnormalities that are not included in the basic training package according to Goals for the education of gynaecologists, ought to be performed by a gynaecologist with additional training and experience.
\end{abstract}

Keywords Diagnostic imaging · Endometrium . Hysteroscopy · (Leio)myoma · Submucous myoma . Surgical procedures · Treatment outcome - Ultrasonography . Uterine haemorrhage $\cdot$ Uterine neoplasms

A. L. Thurkow $(\bowtie) \cdot$ C. F. Admiraal • M. H. Emanuel

P. J. M. van Kesteren $\cdot$ S. Veersema

St. Lucas Andreas Ziekenhuis Amsterdam,

J. Tooropstaart 161 ,

1061 AE Amsterdam, The Netherlands

e-mail: thurkow@planet.nl

\section{Introduction}

This review formed the basis of the model protocol "Submucous myomas: diagnosis and therapy" of the Dutch Working Party on Gynaecological Endoscopy and Minimal Invasive Surgery (WGE, also referred to as the Dutch Society of Gynaecological Endoscopy and Minimal Invasive Surgery) of the Dutch Society of Obstetrics and Gynaecology (NVOG), that was accepted by the NVOG on the 20th September 2006.

The recommendations given in the guideline have been reviewed according to the NVOG guideline for setting up guidelines [1] and classified according to the strength of the scientific evidence in classes A1, A2, B, C or D.

This protocol aims at producing recommendations on the diagnostic and therapeutic approach based on the critical review of scientific research. In this process the principles of minimal invasiveness are given additional weight, both in diagnosis and in therapy, as well as in the prevention of complications. The advice and recommendations have been formulated for national use in the Netherlands and are intended for official use by Dutch gynaecologists only, without any pretension to be applied outside the Netherlands.

\section{Review of the available information}

In the Cochrane Library and the Cochrane Register of controlled studies no publications were found on this specific subject; one review was found about the role of gonadotropin-releasing hormone $(\mathrm{GnRH})$ analogues in the treatment of myomas in general. Moreover, a PubMed search (1966-2002) in Medline was performed. Likewise, non-systematic cross-references were searched for in Medline journals as well as in journals not participating in the Medline database. 
The subject was discussed on two separate occasions during a consensus meeting of experts in the field of gynaecological endoscopy: the "Witte Raaf" convention in Noordwijk, the Netherlands (7-8 March 2002 and 13-14 March 2003).

Clinical points for attention

- preoperative assessment

- treatment options

- prevention of complications of treatment

\section{Definitions}

Fibroids or (leio)myomata are benign tumours of the uterine muscle that can be divided according to their localisation in the uterine wall: submucous myomas (located under the mucosal layer and protruding into the uterine cavity), subserosal (under the serosal layer and protruding into the abdominal cavity) and intramural (in the uterine wall).

A further subclassification of submucous myomas depends on the degree of intramural involvement of the tumour: types 0, I and II (Fig. 1) [2]. Although alternative classifications have been used by others [3], the former is most frequently referred to in the international literature.

\section{Aetiology and pathology}

The precise aetiology of myomas is unknown. Some data, however, indicate that leiomyomas originate from a single neoplastic stem cell of the smooth muscle tissue of the myometrium [4]. Although the exact factors triggering myomatous neoplasia are unknown, oestrogens, progestins and growth factors [epidermal growth factor (EGF) and insulin-like growth factor (IGF)] all appear to play a role in the growth of fibroids.

In the literature increasing evidence can be found that suggests a genetic component in the aetiology of uterine leiomyomata, both in the primary origin and the growth potential. The first chromosome aberration that was shown to be a specific abnormality was the $1(12 ; 14)(\mathrm{q} 14-\mathrm{q} 15$; q23-q24) translocation, in 1988 [5]. In the following years numerous publications have reported cytogenetic, molecular and genetic linkage data supporting and accounting for the evidence for genetic predisposition that had been found before, in epidemiological studies, including familial clustering and racial prevalence [6-8]. Probably, the most clinically important syndrome known presently for myomas is the autosomal dominant hereditary disease hereditary leiomyomatosis and renal cell carcinoma (HLRCC) [8].

\section{Epidemiology}

In up to $25 \%$ of cases, fibroids can produce clinical symptoms [9]; asymptomatic myomas have been stated to exist in $20 \%$, up to as many as $70 \%$, of cases, in one study [10]. Myomas are found almost exclusively during the reproductive period, with a progressive increase after the fourth decade.

Worldwide, myomas are still by far the most frequent indication for a hysterectomy: in Australia 21.7\% [11], in the USA 27\% [12], and in Finland 50\% [13]. Unfortunately, the studies are insufficiently stratified according to the location of the pathology. A number or risk factors are mentioned in the literature for both the existence (positive family history, black race, radiation) and the growth (nulliparity, obesity) of fibroids. These are, however, not specific for the submucous localisation and, partly, are inadequately studied.

\section{Symptoms}

Only $20-50 \%$ of all myomas produce symptoms, and it is the authors' impression that in these data the submucous varieties are over-represented, despite the fact that these

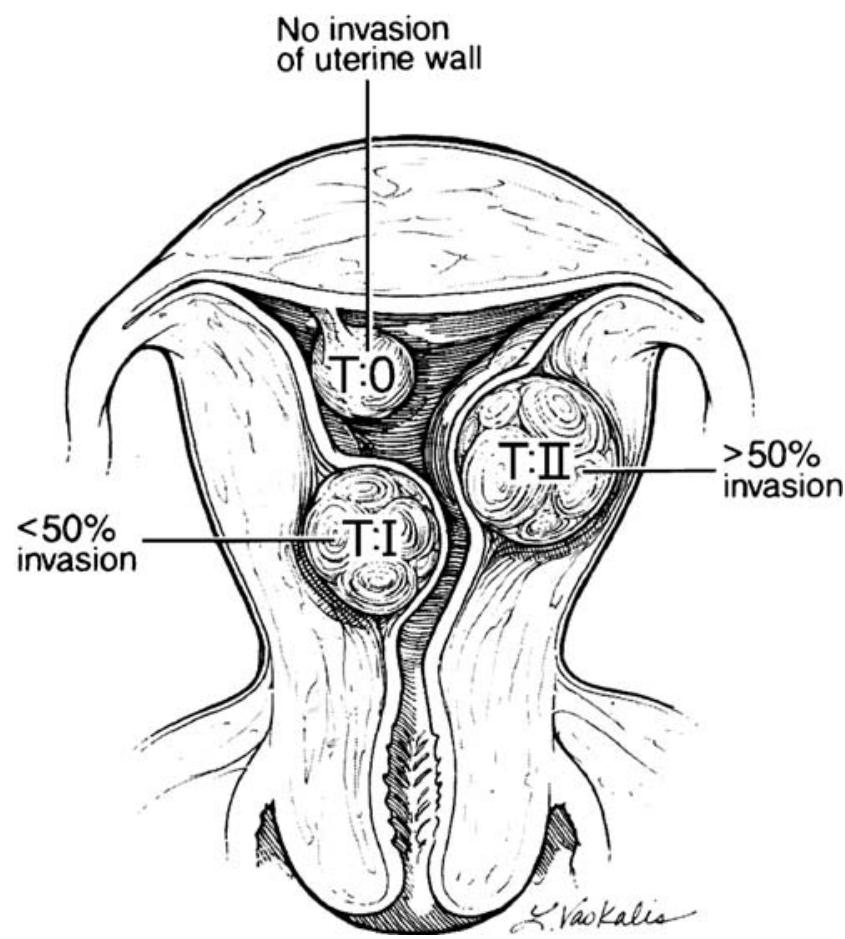

Fig. 1 European Society for Gynaecological Endoscopy (ESGE) classification of submucous myomas, according to intramural extent (in percentage): type $0,0 \%$; type I, $<50 \%$; type II, $>50 \%$ [reprinted with permission of the American Society for Reproductive Medicine (ASRM): Fertil Steril 2000] 
have the least frequent incidence $(5-10 \%)$. For that matter, as a result of diagnostic shortcomings, insufficient data are available on the real prevalence of submucous myomas and their contribution to the total symptomatology. For this prevalence, values between $7.8 \%$ and $29.9 \%$ can be found in the literature [14-16]. Most authors, however, do not differentiate between patients visiting their centre directly, or being referred to their centre by the general practitioner in the case of abnormal uterine blood loss, and the secondary referrals by colleagues. Since, in the latter group, the population is highly selected, it is important to make this distinction. In the primary referral group a total prevalence of submucous myomas of $14.7 \%(n=675)$ was found [3].

\section{Abnormal uterine blood loss}

Approximately $30 \%$ of women are said to complain about heavy menstrual periods without further specification of the localisation in cases of fibroids [17]. One the other hand $40 \%$ of women with more than $200 \mathrm{ml}$ menstrual blood loss are found to have myomas [18]. Only in a secondary referral group were more submucous myomas found in a group of patients with menorrhagia than in those with metrorrhagia [3].

Although it has been suggested that bleeding problems in myomas are specifically associated with a submucous localisation, this is doubted by others [19]. For instance, in recent studies, in only $40 \%$ of patients undergoing hysterectomy for fibroids and menorrhagia were submucous myomas actually found [20].

Little is known concerning a possible causal relationship between fibroids and blood loss. Earlier studies assumed the hypothesis that ulceration of either the mucosa overlying a submucous myoma or the opposing endometrium could be responsible for the bleeding. With hysteroscopic examination, however, this phenomenon is rarely seen.

The association between myomas and hyperplastic changes in the endometrium that has been suggested in the past has never been confirmed by other studies either [19-21]. Other possible explanations include enlargement of the endometrial surface and venous congestion due to compression, which could elucidate how entities other than submucous myomas can cause bleeding.

\section{Dysmenorrhoea}

Dysmenorrhoea appears to be a complaint that is more specifically associated with submucous myomas. It is assumed that contractions as a result of the tendency of the uterus to expel an intracavitary structure form the main explanation for the existing pain symptoms [19].
In cases of dysmenorrhoea a significant over-representation of submucous myomas is found [3].

\section{Subfertility}

The discovery of a submucous myoma in a woman with an unfulfilled wish for childbearing is an attractive reason to treat the abnormality as a possible cause of her problem. Pregnancy rates between $31 \%$ and $65 \%$ have been mentioned after (hysteroscopic and laparoscopic) myomectomy, but there have been no randomised studies [19, 22].

The same lack of evidence is found for the relationship between the rate of miscarriage and the presence of myomas. In retrospective studies a reduction of loss is found after myomectomy, from $73 \%$ to $13 \%$ [23] and $60 \%$ to $24 \%$ [24], respectively, but there are no prospective or randomised trials to support these results. Submucous myomas tend to be more likely to cause recurrent miscarriage, but evidence for this relationship is even more limited [22].

Strangely enough, the results of hysteroscopic, laparoscopic and open surgery are not significantly different from one another [25]. A causal relationship has never been proven. Although $27-40 \%$ of women with multiple fibroids have been described as being subfertile, in the majority of cases other additional possible causes can be established [17]. A recent meta-analysis shows that only myomas with a submucous or intracavitary component are associated with impaired procreational potential, and that hysteroscopic treatment may well be beneficial in these cases [26]

\section{Diagnosis}

\section{Dilatation and curettage}

Dilatation and curettage (D \& C) should no longer be used for the diagnosis in the case of myoma but should be reserved as an instrument for the retrieval of endometrial tissue for histological examination in the absence of focal abnormality [3, 27-29].

\section{Ultrasound}

More and more diagnostic hysteroscopies and curettages are now avoided by the ruling out of polyps, myomas or malignancies with the use of transvaginal ultrasound (NVOG guideline "Abnormaal bloedverlies in de postmenopause": "Abnormal bleeding in postmenopause" [30]).

The mean sensitivity of transvaginal ultrasound for the diagnosis of myomas is $94 \%$ (range $62-100 \%$ ), with a specificity of $98 \%$ [positive predictive value (PPV) 82 90\%, negative predictive value (NPV) 96-98\%] [31-33]. 
In the diagnosis of intracavitary abnormalities a likelihood ratio of 0.04 was found for a normal transvaginal ultrasound and 9.09 for an abnormal ultrasound, in comparison with hysteroscopy as the gold standard [3].

\section{Sonohysterography}

Sonohysterography or saline infusion sonohysterography (SIS) is an ultrasound examination performed after the uterine cavity has been filled with normal physiological saline solution as a contrast medium. In comparative studies between various methods of intra-uterine diagnostic procedures, SIS appears to be more reliable than transvaginal ultrasound alone and as predictive as hysteroscopy. The reliability of transvaginal ultrasound increases with the addition of saline solution as a contrast medium [17, 3336]. In a meta-analysis by de Kroon et al. the following data were established in this respect: sensitivity $0.95(95 \%$ CI 0.93 to 0.97 ), specificity 0.88 (95\% CI 0.85 to 0.92 ), likelihood ratios 8.23 (95\% CI 6.2 to 11$)$ and 0.06 (95\% CI 0.04 to 0.09$)$ [37].

In a study of 52 women, even with abdominal sonohysterography immediately preceding a hysterectomy (with histology as the gold standard) $100 \%$ values were found for sensitivity, specificity and positive and negative predictive values [32].

With the aid of saline contrast agent the presence, size and location of the myoma can be assessed more accurately $[34,38]$. As a consequence, the operability and risk of complications are easier to determine, as is the distance between the fibroid and the serosa, which is also important preoperative information $[3,39]$.

The advantages over hysteroscopy include the ability to visualise both uterine cavity and wall simultaneously, the fact that the procedure is possible even in the case of heavy bleeding, and the lower burden it imposes on the patient in terms of pain [40], but it remains to be proven whether this is still valid in comparison with the vaginoscopic, or notouch, technique in hysteroscopy. Systematic studies are not available, but the existing literature on the subject suggests that the differences will then disappear of perhaps even turn around in favour of hysteroscopy [41, 42].

\section{Hysteroscopy}

On account of substantial evidence, many authors consider a diagnostic hysteroscopy to be the gold standard for diagnosis in the uterine cavity [29, 43-45], but this diagnostic procedure has its limitations (see Sonohysterography).

For the determination of the presence of submucous myomas in several studies, sensitivity, specificity and positive and negative predictive values of hysteroscopy did not differ significantly from those of SIS [31, 32, 40], although, in other studies, these were lower: sensitivity $82 \%$, specificity $87 \%$ [36].

Hysterosalpingography

Although, especially in infertility workup, the first suggestion of a submucous myoma may well arise in a hysterosalpingography (HSG), it is not to be recommended as a primary investigation item due to the extremely low reliability with respect to intracavitary abnormalities, where up to $32 \%$ of false positive results have been described [46-49]. Moreover, this procedure has the disadvantage of being a radiation burden to the patient.

\section{Magnetic resonance imaging}

Although some authors advocate the use of magnetic resonance imaging (MRI) for the diagnosis of submucous myomas, its limited availability and its costs will limit the routine use of this procedure. Nevertheless, the use of MRI in the case of myomas appears to be worthwhile for the precise assessment of the size and intramural extent. For this purpose it is superior to all former techniques [34]. This can therefore be taken into consideration and MRI can be recommended as a first choice diagnostic procedure in all advanced minimally invasive surgery (e.g. large type II myomas). If available, MRI could, at any rate, be an alternative in those cases in which SIS has failed or is contra-indicated.

\section{Puncture biopsy}

Under ultrasound guidance, both through the vaginal and the abdominal approach, it is possible for the surgeon to perform histological examination of a myoma to differentiate it from adenomyosis or sarcoma [50]. It is, however, questionable whether the early detection of adenomyosis has such additional value that an invasive form of diagnostics can be justified. The same applies to the detection of sarcomas, in view of the extreme rarity of this form of malignancy, especially in premenopause. In addition, with sarcomas, there is also concern about possible spill. Moreover, a biopsy might not be representative, and thus adenomyosis elsewhere in the myometrium can never be excluded. For these reasons the diagnostic modality of puncture biopsy has not been broadly adopted.

Colour pulsed Doppler ultrasound

Doppler ultrasound offers one the possibility to determine blood flow profiles in normal and abnormal organs in the small pelvis [51]. Although some authors suggest that adenomyosis and sarcomas can be distinguished from 
myomas on account of differences in flow indices [52], these data have not been confirmed in later studies, and there is lack of consensus concerning the methodology used.

\section{Three-dimensional ultrasound}

The possibilities of 3-D ultrasound seem promising. In the literature to date, however, no evidence can be found for a substantial additional value in comparison with the aforementioned techniques. In a study of endometrial polyps, both 3-D ultrasound and 3-D sonohysterography had a higher specificity than the comparable two-dimensional technique $(69.5 \%$ vs $88.8 \%$ and $94.1 \%$ vs $100 \%$, respectively); the 2-D sonohysterography still appeared to score better than the 3-D conventional ultrasound [50]. For submucous myomas no comparative data are available.

\section{Therapy}

Classic approaches: myomectomy, embolisation, hysterectomy

In the literature there is consensus concerning the fact that myomectomy, embolisation and hysterectomy for smaller submucous myomas can be considered to be over-treatment [29]. These treatment options are reserved for those cases where the fibroids are too large or not responding to pretreatment. An extensive discussion of these techniques is beyond the scope of this review, since they are not specific for the submucous localisation of myomas.

With respect to embolisation, a remark should be made concerning the fact that some investigators consider a submucous myoma to be a (relative) contraindication in view of the risk of necrosis in the uterine cavity, with expulsion and possibly the subsequent increased risk of septicaemia [53, 54].

For all forms of surgical treatment of myomas in patients who still wish to conceive, the potential consequences for a pregnancy should be taken into account, such as uterine rupture and, theoretically, placenta accreta or increta. Systematic research on this subject is not available, merely case reports $[55,56]$.

\section{Hysteroscopic myomectomy}

As the least invasive treatment modality a hysteroscopic transcervical resection of myomas (further referred to as TCRM) is an obvious approach in the case of submucous localisation. For the treatment of menorrhagia success rates between $71 \%$ and $96 \%$ have been claimed in the literature [3, 57-59]. Chances of one treatment being sufficiently effective appear to depend strongly on the degree of intramural extent: type 0 96\%; type I $74 \%$; type II $67 \%$ ( $n=93 ; 2-8$ year follow-up) [58]. The deeper the myoma penetrates into the myometrium, the higher the chances are to end up with an incomplete resection and hence the necessity to perform a repeat procedure: $0 \%$ in type 0 up to $36 \%$ in type II [3].

For that matter, there are indications that, even after an incomplete resection, the symptoms may disappear (through spontaneous regression or resorption of fibroid tissue): in one study this was the case in up to $66 \%$ of cases [60]. Whether there is a maximum to the amount of tissue that be left behind is not clear from the article.

Moreover, the success is also dependent on the presence of any other myomas that might increase chances of recurrence of the problem. It has been suggested that TCRM is most successful in uteri of normal size with no more than two submucous myomas and that, perhaps, this treatment should be limited to this specific group of patients [3].

In addition there is a limit to the size of each individual fibroid that is suitable for hysteroscopic resection: 4 to $5 \mathrm{~cm}$ is mostly considered to be the maximum feasible diameter in this respect $[2,59]$. With larger diameters, medical pretreatment can be considered in order to reduce the size to fall within the range of these maxima (see 2,7).

\section{Precautions necessary with therapy}

The precautionary measures to be taken all are related to one on more of the following complications that could thus be prevented: intravasation, infection, perforation and bleeding.

\section{Medical pre-treatment}

In the event of a "trans-urethral resection" ("TUR") syndrome (see Use of distension media and instrumentation), the duration of the procedure and the location of the myoma appear to be the most important risk factors [3]. Others mention the size of the myoma to be an additional factor, but it is most likely that there is a correlation between size and duration of the procedure. Since the speed of removal of tissue depends on its volume, this correlation is probably exponential: the relationship between the volume and the radius of a (spherical) myoma is determined by the formula $4 / 3 \pi r^{3}$. Preoperative medical therapy can reduce the size of the myoma that is to be removed.

Although many drugs have been studied, clinically only $\mathrm{GnRH}$ analogues are capable of significantly reducing the size of myomas, with percentages between 30 and 70, when these had been used for 3 to 4 months preceding surgical 
intervention [61-66]. Although, in these studies, no distinction is made in fibroid location and no endoscopic procedures were involved, it seems that part of the results may be extrapolated to be applied to submucous myomas and TCRM as well.

Additional advantages of GnRH analogues are the correction of existing pre-operative anaemia and reduction of intra-operative blood loss [67-69].

There are no randomised controlled prospective trials that specifically prove the effect of GnRH analogue reduction on submucous myomas. Retrospective studies, however, have suggested the existence of this effect [7072]. In one study no additional benefit of pre-treatment was determined for either the patient or the surgeon in submucous myomas with a diameter smaller than $3 \mathrm{~cm}$ [73]. Whether or not the pre-operative reduction of a myoma is indicated in every case cannot be adequately answered on the basis of the actual literature available. Contrary to what might be expected, the addition of hormonal medication ("add-back" therapy) for the vasomotor symptoms caused by GnRH analogues appears to have no adverse effect on the myoma reduction $[74,75]$.

Unfavourable localisation of the myoma, e.g. in the cornual area, is mentioned by some authors as another indication for pre-treatment to prevent perforation [76].

In view of the high costs and the side effects of $\mathrm{GnRH}$ analogues, it seems reasonable to determine indications and to limit administration to this selected group of indications.

From the aforementioned data the following indications have been formulated [76]:

- subfertility

- myomas with a diameter of $4 \mathrm{~cm}$ and above

- an unfavourable location in the uterine cavity, e.g. the cornual area

- anaemia due to abnormal bleeding

- type II myomas

These indications are reinforced when they occur in combination with each other.

Use of distension media and instrumentation

\section{Distension medium}

In TCRM with hypotonic distension media there is a consensus about the need to use a system that enables the assessment of the amount of inflow and outflow of the distension medium as a measure of the degree of intravasation in order to prevent fluid overload [77]. Systematic research in this field is lacking. In the meantime, systems have been developed that use bipolar electrical energy, with the advantage of the possibility to use isotonic solutions instead. Although, as far as intravasation is concerned, the safety margins are probably larger, it remains even then advisable to control the fluid load, especially in the case of existing cardiopulmonary risk factors [78]. The consequences of intravasation can be subdivided into volume overload, which is to be expected in every medium in the case of excessive infusion, and a shift in electrolytes that may occur in non-isotonic media. The latter could lead to the so-called "TUR" syndrome, named after the trans-urethral resection in which procedure this entity was first reported [79].

The disruption of the electrolyte balance through the intravasation of non-isotonic, non-conductive fluids used as distension media can potentially cause serious organ damage. There appears to be a linear correlation between the intravasation of an electrolyte free (non-isotonic) fluid and the occurrence of hyponatraemia: approximately a $1 \mathrm{mmol} / \mathrm{l}$ drop in $\mathrm{Na}$ concentration per $100 \mathrm{ml}$ of fluid loss. Moreover, with as little as $500 \mathrm{ml}$ of fluid deficit and above, oedema of the brain has been found to be visible on computerised axial tomography (CAT) scan $[3,80,81]$.

Consequences of hyponatraemia may be:

- 120-125 mmol/l, discomfort; nausea; headache

- 110-120 mmol/l, headache; lethargy; confusion

- $\quad<110 \mathrm{mmol} / \mathrm{l}$, insult; delirium; coma (beware of cardiac rhythm changes in cases of hypokalaemia)

Assuming a mean population value of $140 \mathrm{mmol} / \mathrm{l}$ for $\mathrm{Na}^{+}$, a value of $125 \mathrm{mmol} / \mathrm{l}$ corresponds to approximately $1,500 \mathrm{ml}$ fluid deficit [3].

Probably, the determination of the osmolarity is a better measure for the amount of electrolyte shift [82].

The above-mentioned leads to the arbitrary limits for the maximum deficit that is acceptable with electrolyte free distension fluid. The Dutch WGE expert group reached a consensus on this subject in 2002, which corresponds with the one that has been reached between the Germanspeaking nations [77], the guidelines of the American College of Obstetrics and Gynecology (ACOG) [78] and the Scottish Royal College of Physicians [83]:

- $>500 \mathrm{ml}$ - intensification of vigilance and monitoring during the procedure

- facultative administration of mannitol 20\% [84]

- $>1000 \mathrm{ml}$ - aiming at ending the procedure (max. intravasation $1,500 \mathrm{ml}$ )

- administration of diuretics

- administration of $\mathrm{NaCl} 2.5 \%$ under guidance of electrolyte assessment

In order to be able to determine this deficit in rinsing fluid, it is advisable to use an automatic pump system that continuously visualises flow rate and the amount of inflow and outflow of the distension medium.

Which form of anaesthesia is optimal is not clear from the literature either. On one hand, with regional anaesthesia 
symptoms the subjective wellbeing of the patient is a sensitive monitoring system (e.g. dyspnoea is an early symptom of intravasation); on the other hand the first symptoms of hyponatraemia become clear more rapidly than with general anaesthesia.

Bipolar energy systems have the great advantage of permitting the use of normal saline solution as the distension medium but are not yet widely used. On the basis of favourable clinical experience and the ongoing developments that are taking place in the leading industries in this area, bipolar systems appear very promising in terms of a wider window of safety and fewer serious complications when intravasation occurs $[85,86]$. The ACOG advises the acceptance of a maximum deficit of 2,500 ml saline solution [78]. Results of clinical studies to substantiate this recommendation, however, are not available.

\section{Perforation}

Chances of perforation probably increase accordingly with the decrease in the distance between myoma and serosa. An arbitrary safe margin of $8 \mathrm{~mm}$ has been mentioned for this distance in the literature [87]. The smaller this distance is, the more restraint and vigilance has to be maintained, and the surgeon may consider performing the procedure under laparoscopic or ultrasound guidance. In the case of perforation, it is usually advisable to end the procedure and continue at a later stage, unless there is suggestion of a bowel lesion - in that case, laparoscopy and, if there is doubt, even a laparotomy, is recommended [78, 83].

\section{Antibiotic prophylaxis}

The incidence of infection in hysteroscopic operations is higher than in diagnostic procedures but still very low [88]. In transcervical resection of the endometrium (TCRE), the use of antibiotic prophylaxis has been studied and has not been proven to be meaningful in the prevention of clinically manifested infections, although there was a significant reduction in the incidence of bacteraemia ( $2 \%$ vs $16 \%$ ) [89]. In view of the latter somewhat paradoxical finding, it might be argued that a clinical significance could be found in a larger study group.

Whether these data may simply be extrapolated to TCRM cases is questionable, but the smaller wound surfaces in these procedures make it unlikely that the risks will be much greater. In contrast a few case reports of serious, incidental fatal infections have caused some authors to give antibiotic prophylaxis all the same [90, 91].

It may be considered to recommend antibiotic prophylaxis on these grounds and on account of the reduction in bacteraemia until more is clarified about the use of this measure, especially if there are possible plans for further child bearing. This is in concordance with both the aforementioned Dutch guideline and the RCOG guideline no. 5 on menorrhagia, which both also tend to recommend antibiotics in hysteroscopic procedures on account of the suggestive extrapolation from hysterectomy data $[29,92]$.

Vasoconstrictive agents and other drugs controlling bleeding

Bleeding in TCRM is a rare complication: 0.4\% [55], although some authors report values up to $5 \%$. In a Dutch study in 82 hospitals, this complication was found in no more than $0.75 \%$ of cases [88].

Vasoconstrictive agents are said to have a preventive effect on bleeding. For this purpose adrenaline 1:200000 has been advised, but its use has never been adequately evaluated.

Intravenous administration of $500-1,000 \mathrm{mg}$ of tranexamic acid (Cyclokapron) is known to decrease the amount of postoperative bleeding, but, in the literature, very few data can be found on its application in TCRM. The ACOG recommends possible intracavitary administration of this drug, but without further reference [78].

In order to prevent postoperative bleeding after TCRM a $30 \mathrm{ml}$ Foley catheter may be used on indication, or a specially designed intra-uterine balloon stent (Cook) for $6 \mathrm{~h}$ to $12 \mathrm{~h}$ after the procedure as a tamponade device for the intra-uterine wound bed. In most cases, however, the bleeding will come to an acceptable level within minutes after the procedure, which period therefore can best be awaited before any measures are taken.

\section{Expertise and training}

The necessary expertise for the treatment of submucous myomas is described in the Goals for the basic training package in the education of the Gynaecologist as these have been formulated by the Educational Council of the Dutch Society of Obstetrics and Gynaecology. From the recommendations in this report the TCRM of small type 0 and I myomas can be considered to belong to the basic training package of each gynaecologist, but the treatment of type II and/or large myomas is to be restricted to gynaecologists with additional training and experience.

\section{Conclusions and practical recommendations}

\section{Diagnosis}

1. In the case of submucous myomas, transvaginal ultrasound is the initial imaging technique of choice (B). 
2. For a more accurate diagnostic visualisation, especially if this fails in conventional ultrasound and as an adequate preparation for operative treatment, the addition of physiological saline solution as a contrast medium (SIS: saline infusion sonohysterography) is recommended (B).

3. Diagnostic hysteroscopy is almost equally effective for this purpose (B) and, moreover, has the advantage of ample evidence to be a good test for the simple detection and exclusion of intra-uterine abnormality (B).

4. MRI is a less readily available alternative, with a reliability that, specifically for submucous myomas, is superior to that of SIS and hysteroscopy and can be used preoperatively on indication of certain surgical procedures $(\mathbf{B})$.

\section{Therapy}

1. Submucous myomas with a diameter of $4 \mathrm{~cm}$ and less should be removed hysteroscopically (B).

2. In the case of larger fibroids, preoperative reduction is possible with GnRH analogues (A2), and, in the case of additional risk factors (subfertility, unfavourable location, anaemia, type II), pre-treatment with these drugs should be taken into consideration (B).

3. For multiple myomas, patients should be counselled about an increased recurrence risk, and alternative therapy, such as hysterectomy, can be taken into consideration $(\mathbf{C})$. If there are child bearing intentions, restraint is mandatory to a degree that is in proportion to the degree of intramural extent (which, by the way, in addition, decreases the strength of the indication accordingly) (B).

4. When a hypotonic distension medium is used in myoma removal, an automated pump system is recommended that carefully monitors the difference between inflow and outflow, aiming at limitation of the deficit up to $1,000 \mathrm{ml}$ (at any rate, no more than $1,500 \mathrm{ml})(\mathbf{D})$. Possible additional measures to be taken in case of an increasing deficit of distension medium include the use of mannitol, physiological saline solution and/or diuretics (C).

5. Antibiotic prophylaxis is recommended $(\mathbf{C})$.

6. In the case of serious post-operative blood loss, intrauterine tamponade with a balloon catheter may be considered (D).

7. Hysteroscopic surgery under laparoscopic or ultrasound guidance is rarely necessary but may be taken into consideration in specific indications (D).

8. Surgery for abnormalities that are not included in the basic training package according to the aforementioned Goals for the education of gynaecologists ought to be performed by a gynaecologist with additional training and experience (D).

\section{Explanation of keys used for the grading of recommendations}

A1: based on meta-analyses that contain at least several randomised studies of level A2, and in which the results of the individual studies are consistent.

A2: of good quality and with sufficient volume and consistency.

B: based on randomised controlled trials of lesser quality or insufficient volume or other comparative studies (non-randomised; cohort studies, case-control studies)

C: based on non-comparative studies

D: based on expert opinion and respected authorities

\section{References}

1. NVOG (2004) Leidraad Opstellen Richtlijnen: procedure en stramien (report)

2. Wamsteker K, Emanuel MH, de Kruif JH (1993) Transcervical hysteroscopic resection of submucous fibroids for abnormal uterine bleeding: results regarding the degree of intramural extension. Obstet Gynecol 82(5):736-740

3. Emanuel MH (1998) Submucous myomas and abnormal uterine bleeding, epidemiology, diagnosis and treatment (dissertation). Universiteit van Amsterdam

4. Townsend DE, Sparkes RS, Baluda MC, McClelland G (1970) Unicellular histogenesis of uterine leiomyomas as determined by electrophoresis by glucose-6-phosphate dehydrogenase. Am J Obstet Gynecol 107(8):1168-1173

5. Heim S, Nilbert M, Vanni R, Floderus UM, Mandahl N, Liedgren $\mathrm{S}$ et al (1988) A specific translocation, $\mathrm{t}(12 ; 14)(\mathrm{q} 14-15 ; \mathrm{q} 23-24)$, characterizes a subgroup of uterine leiomyomas. Cancer Genet Cytogenet 32(1):13-17

6. Kurbanova MK, Koroleva AG, Sergeev AS (1989) [Genetic analysis of the predisposition to uterine myoma. Prevalence and morbidity]. Genetika 25(6):1122-1124

7. Marshall LM, Spiegelman D, Barbieri RL, Goldman MB, Manson JE, Colditz GA et al (1997) Variation in the incidence of uterine leiomyoma among premenopausal women by age and race. Obstet Gynecol 90(6):967-973

8. Stewart EA, Morton CC (2006) The genetics of uterine leiomyomata: what clinicians need to know. Obstet Gynecol 107(4):917921

9. Stewart EA (2001) Uterine fibroids. Lancet 357(9252):293-298

10. Day BD, Dunson DB, Hill MC, Cousins D, Schectman JM (2003) High cumulative incidence of uterine leiomyoma in black and white women: ultrasound evidence. Am J Obstet Gynecol 188 (1):100-107

11. Renwick M (1991) Variations in surgery rates: implications for quality. Aust Clin Rev 11(4):159-163

12. Pokras R, Hufnagel VG (1988) Hysterectomy in the United States, 1965-84. Am J Public Health 78(7):852-853

13. Luoto R, Kaprio J, Keskimaki I, Pohjanlahti JP, Rutanen EM (1994) Incidence, causes and surgical methods for hysterectomy in Finland, 1987-1989. Int J Epidemiol 23(2):348-358 
14. Barbot J, Parent B, Dubuisson JB (1980) Contact hysteroscopy: another method of endoscopic examination of the uterine cavity. Am J Obstet Gynecol 136(6):721-726

15. (1984) Hysteroscopy: Principles and practice. Lippincott, Philadelphia

16. Motashaw ND, Dave S (1990) Diagnostic and therapeutic hysteroscopy in the management of abnormal uterine bleeding. J Reprod Med 35(6):616-620

17. Buttram VC Jr, Reiter RC (1981) Uterine leiomyomata: etiology, symptomatology, and management. Fertil Steril 36(4):433-445

18. Rybo G, Leman J, Tibbin R (1985) Epidemiology of menstrual blood loss. In: Baird DT, Michie EA (eds) Mechanisms of menstrual bleeding. Raven Press, New York p.181-193

19. Lumsden MA, Wallace EM (1998) Clinical presentation of uterine fibroids. Baillieres Clin Obstet Gynaecol 12(2):177-195

20. Lumsden MA (1992) Fibroids and menorrhagia. In: Shaw RW (ed) Uterine fibroids: time for review. Parthenon Publishing, Carnforth, UK p 57-68

21. Deligdish L, Loewenthal M (1970) Endometrial changes associated with myomata of the uterus. J Clin Pathol 23(8):676-680

22. Kolankaya A, Arici A (2006) Myomas and assisted reproductive technologies: when and how to act? Obstet Gynecol Clin North Am 33(1):145-152

23. Vercellini P, Maddalena S, De Giorgi O, Pesole A, Ferrari L, Crosignani PG (1999) Determinants of reproductive outcome after abdominal myomectomy for infertility. Fertil Steril 72(1):109-114

24. Li TC, Mortimer R, Cooke ID (1999) Myomectomy: a retrospective study to examine reproductive performance before and after surgery. Hum Reprod 14(7):1735-1740

25. Donnez J, Jadoul P (2002) What are the implications of myomas on fertility? A need for a debate? Hum Reprod 17(6):1424-1430

26. Pritts EA (2001) Fibroids and infertility: a systematic review of the evidence. Obstet Gynecol Surv 56(8):483-491

27. Word B, Gravlee LC, Wideman GL (1958) The fallacy of simple uterine curettage. Obstet Gynecol 12(6):642-648

28. Stock RJ, Kanbour A (1975) Prehysterectomy curettage. Obstet Gynecol 45(5):537-541

29. RCOG (1999) The management of menorrhagia in secondary care. RCOG Bookshop at the Royal College of Obstetricians and Gynaecologists, UK

30. NVOG (2003) Richtlijn 4. Abnormaal bloedverlies in de postmenopauze (herzien) (report)

31. Schwarzler P, Concin H, Bosch H, Berlinger A, Wohlgenannt K, Collins WP et al (1998) An evaluation of sonohysterography and diagnostic hysteroscopy for the assessment of intrauterine pathology. Ultrasound Obstet Gynecol 11(5):337-342

32. Cicinelli E, Romano F, Anastasio PS, Blasi N, Parisi C, Galantino P (1995) Transabdominal sonohysterography, transvaginal sonography, and hysteroscopy in the evaluation of submucous myomas. Obstet Gynecol 85(1):42-47

33. Dueholm M, Lundorf E, Olesen F (2002) Imaging techniques for evaluation of the uterine cavity and endometrium in premenopausal patients before minimally invasive surgery. Obstet Gynecol Surv 57(6):388-403

34. Dueholm M, Lundorf E, Hansen ES, Ledertoug S, Olesen F (2001) Evaluation of the uterine cavity with magnetic resonance imaging, transvaginal sonography, hysterosonographic examination, and diagnostic hysteroscopy. Fertil Steril 76(2):350-357

35. De Vries LD, Dijkhuizen FP, Mol BW, Brolmann HA, Moret E, Heintz AP (2000) Comparison of transvaginal sonography, saline infusion sonography, and hysteroscopy in premenopausal women with abnormal uterine bleeding. J Clin Ultrasound 28(5):217-223

36. Dijkhuizen FP, De Vries LD, Mol BW, Brolmann HA, Peters HM, Moret $\mathrm{E}$ et al (2000) Comparison of transvaginal ultrasonography and saline infusion sonography for the detection of intracavitary abnormalities in premenopausal women. Ultrasound Obstet Gynecol 15(5):372-376
37. de Kroon CD, de Bock GH, Dieben SW, Jansen FW (2003) Saline contrast hysterosonography in abnormal uterine bleeding: a systematic review and meta-analysis. BJOG 110(10):938-947

38. Thurkow AL (1999) Saline infusion sonohysterography (SIS). In: Slager E, (ed). Infertiliteit, Gynaecologie en Obstetrie anno 1999. Organon, Oss

39. de Blok S, Wamsteker K (1992) [Hysteroscopy]. Ned Tijdschr Geneeskd 136(34):1640-1644

40. Widrich T, Bradley LD, Mitchinson AR, Collins RL (1996) Comparison of saline infusion sonography with office hysteroscopy for the evaluation of the endometrium. Am J Obstet Gynecol 174(4):1327-1334

41. Bettocchi S (1996) New era of office hysteroscopy. J Am Assoc Gynecol Laparosc 3(4, Supplement):S4

42. Sharma M, Taylor A, Di Spiezio SA, Buck L, Mastrogamvrakis G, Kosmas I et al (2005) Outpatient hysteroscopy: traditional versus the 'no-touch' technique. BJOG 112(7):963-967

43. Gimpelson RJ, Rappold HO (1988) A comparative study between panoramic hysteroscopy with directed biopsies and dilatation and curettage. A review of 276 cases. Am J Obstet Gynecol 158(3 Pt 1):489-492

44. Gimpelson RJ, Whalen TR (1995) Hysteroscopy as gold standard for evaluation of abnormal uterine bleeding. Am J Obstet Gynecol 173(5):1637-1638

45. Valle RF (1981) Hysteroscopic evaluation of patients with abnormal uterine bleeding. Surg Gynecol Obstet 153(4):521-526

46. Taylor PJ, Cumming DC (1979) Hysteroscopy in 100 patients. Fertil Steril 31(3):301-304

47. Valle RF (1980) Hysteroscopy in the evaluation of female infertility. Am J Obstet Gynecol 137(4):425-431

48. Randolph JF Jr, Ying YK, Maier DB, Schmidt CL, Riddick DH (1986) Comparison of real-time ultrasonography, hysterosalpingography, and laparoscopy/hysteroscopy in the evaluation of uterine abnormalities and tubal patency. Fertil Steril 46(5):828-832

49. Hoetzinger H (1991) Hysterosonography and hysterography in benign and malignant diseases of the uterus. A comparative in vitro study. J Ultrasound Med 10(5):259-263

50. Wood C, Hurley VA, Fortune DW, Leoni M (1993) Percutaneous ultrasound guided uterine needle biopsy. Med J Aust 158(7):458460

51. Bourne TH (1991) Transvaginal color Doppler in gynecology. Ultrasound Obstet Gynecol 1(5):359-373

52. Kurjak A, Zalud I (1991) The characterization of uterine tumors by transvaginal color Doppler. Ultrasound Obstet Gynecol 1(1):50-52

53. Jones K, Walker WJ, Sutton C (2000) Sequestration and extrusion of intramural fibroids following uterine artery embolisation: a case series. Gynaecol Endoscopy 9(5):309-313

54. McLucas B, Adler L, Perrella R (2001) Uterine fibroid embolization: nonsurgical treatment for symptomatic fibroids. J Am Coll Surg 192(1):95-105

55. Konig M, Meyer A, Aydeniz B, Kurek R, Wallwiener D (2000) Hysteroscopic surgery-complications and their prevention. Contrib Gynecol Obstet 20:161-170

56. West CP (1998) Hysterectomy and myomectomy by laparotomy. Baillieres Clin Obstet Gynaecol 12(2):317-335

57. Broadbent JA, Magos AL (1994) Menstrual loss after hysteroscopic myomectomy. Gynaecol Endoscopy 4:41-44

58. de Blok S, Dijkman AB, Hemrika DJ (1994) Transcervical resection of fibroids (TCRM): results related to hysteroscopic classification. Gynaecol Endoscopy 4:243-246

59. Derman SG, Rehnstrom J, Neuwirth RS (1991) The long-term effectiveness of hysteroscopic treatment of menorrhagia and leiomyomas. Obstet Gynecol 77(4):591-594

60. Dueholm M, Forman A, Ingerslev J (1998) Regression of residual tissue after incomplete resection of submucous myomas. Gynaecol Endoscopy 7(6):309-314 
61. Healy DL, Lawson SR, Abbott M, Baird DT, Fraser HM (1986) Toward removing uterine fibroids without surgery: subcutaneous infusion of a luteinizing hormone-releasing hormone agonist commencing in the luteal phase. J Clin Endocrinol Metab 63 (3):619-625

62. Maheux R, Lemay-Turcot L, Lemay A (1986) Daily folliclestimulating hormone, luteinizing hormone, estradiol, and progesterone in ten women harboring uterine leiomyomas. Fertil Steril 46(2):205-208

63. West CP, Lumsden MA, Lawson S, Williamson J, Baird DT (1987) Shrinkage of uterine fibroids during therapy with goserelin (Zoladex): a luteinizing hormone-releasing hormone agonist administered as a monthly subcutaneous depot. Fertil Steril 48 (1):45-51

64. Friedman AJ, Harrison-Atlas D, Barbieri RL, Benacerraf B, Gleason R, Schiff I (1989) A randomized, placebo-controlled, double-blind study evaluating the efficacy of leuprolide acetate depot in the treatment of uterine leiomyomata. Fertil Steril 51 (2):251-256

65. Hackenberg R, Gesenhues T, Deichert U, Duda V, Sturm G, Schulz KD (1990) [Preoperative reduction of uterine leiomyoma by the GnRH analog goserelin (Zoladex)]. Geburtshilfe Frauenheilkd 50(2):136-139

66. Lethaby A, Vollenhoven B, Sowter M (2001) Pre-operative GnRH analogue therapy before hysterectomy or myomectomy for uterine fibroids. Cochrane Database Syst Rev (2):CD000547

67. Donnez J, Nisolle M, Clerckx F, Casanas-Roux F, Saussoy P, Gillerot S (1994) Advanced endoscopic techniques used in dysfunctional bleeding, fibroids and endometriosis, and the role of gonadotrophin-releasing hormone agonist treatment. $\mathrm{Br} \mathrm{J}$ Obstet Gynaecol 101 [Suppl 10]:2-9

68. Benagiano G, Kivinen ST, Fadini R, Cronje H, Klintorp S, van der Spuy ZM (1996) Zoladex (goserelin acetate) and the anemic patient: results of a multicenter fibroid study. Fertil Steril 66(2):223-229

69. Romer T (1997) [Hysteroscopic myoma resection of submucous myomas with largely intramural components]. Zentralbl Gynakol 119(8):374-377

70. Felberbaum RE, Kupker W, Krapp M, Gehl B, Ludwig M, Diedrich K (2001) Preoperative reduction of uterine fibroids in only 16 days by administration of a gonadotrophin-releasing hormone antagonist (Cetrotide). Reprod Biomed Online 3(1):14-18

71. Parazzini F, Vercellini P, De Giorgi O, Pesole A, Ricci E, Crosignani PG (1998) Efficacy of preoperative medical treatment in facilitating hysteroscopic endometrial resection, myomectomy and metroplasty: literature review. Hum Reprod 13(9):2592-2597

72. Crosignani PG, Vercellini P, Meschia M, Oldani S, Bramante T (1996) GnRH agonists before surgery for uterine leiomyomas. A review. J Reprod Med 41(6):415-421

73. Romer T (1996) [Value of premedication with gonadotropin releasing hormone agonists before transcervical resection of solitary submucous myoma]. Gynakol Geburtshilfliche Rundsch 36(4):194-196

74. Gocmen A, Kara IH, Karaca M (2002) The effects of add-back therapy with tibolone on myoma uteri. Clin Exp Obstet Gynecol 29(3):222-224

75. Palomba S, Pellicano M, Affinito P, Di Carlo C, Zullo F, Nappi C (2001) Effectiveness of short-term administration of tibolone plus gonadotropin-releasing hormone analogue on the surgical outcome of laparoscopic myomectomy. Fertil Steril 75(2):429-433

76. Romer T, Schmidt T, Foth D (2000) Pre-and postoperative hormonal treatment in patients with hysteroscopic surgery. Contrib Gynecol Obstet 20:1-12

77. Kochli OR, Wallwiener D, Brandner P, Bratschi HU, Bronz L, Burmucic R et al (2000) Consensus of diagnostic and operative hysteroscopy. Consensus statements of a joint-meeting of the Societies for Gynecological Endoscopy of Switzerland, Germany and Austria, October 1999. Contrib Gynecol Obstet 20:182-187

78. No authors listed (2005) ACOG technology assessment in obstetrics and gynecology, number 4, August 2005: hysteroscopy. Obstet Gynecol 106(2):439-442

79. Iglesias JJ, Stams UK (1975) [How to prevent the TUR-syndrome (author's transl)]. Urologe A 14(6):287-291

80. Istre O, Bjoennes J, Naess R, Hornbaek K, Forman A (1994) Postoperative cerebral oedema after transcervical endometrial resection and uterine irrigation with $1.5 \%$ glycine. Lancet 344 (8931):1187-1189

81. Istre O, Jellum E, Skajaa K, Forman A (1995) Changes in amino acids, ammonium, and coagulation factors after transcervical resection of the endometrium with a glycine solution used for uterine irrigation. Am J Obstet Gynecol 172(3):939-945

82. Gravenstein D (1997) Transurethral resection of the prostate (TURP) syndrome: a review of the pathophysiology and management. Anesth Analg 84(2):438-446

83. Scottish Intercollegiate Guidelines Network, Royal College of Physicians. Hysteroscopic surgery. 1 April 1999. Edinburgh, SIGN (report)

84. Loffer FD, Bradley LD, Brill AI, Brooks PG, Cooper JM (2000) Hysteroscopic fluid monitoring guidelines. J Am Assoc Gynecol Laparosc 7(3):438

85. Kung RC, Vilos GA, Thomas B, Penkin P, Zaltz AP, Stabinsky SA (1999) A new bipolar system for performing operative hysteroscopy in normal saline. J Am Assoc Gynecol Laparosc 6 (3):331-336

86. Feste JR, Lotze EC (1998) Clinical experience with the (OPERA) StarSL using saline irrigation fluid for OPERA. Prim Care Update Ob Gyns 5(4):205-206

87. Brandner P, Neis KJ, Diebold P (2000) Hysteroscopic resection of submucous myomas. Contrib Gynecol Obstet 20:81-90

88. Jansen FW, Vredevoogd CB, van Ulzen K, Hermans J, Trimbos JB, Trimbos-Kemper TC (2000) Complications of hysteroscopy: a prospective, multicenter study. Obstet Gynecol 96(2):266-270

89. Bhattacharya S, Cameron IM, Parkin DE, Abramovich DR, Mollison J, Pinion SB et al (1997) A pragmatic randomised comparison of transcervical resection of the endometrium with endometrial laser ablation for the treatment of menorrhagia. $\mathrm{Br} \mathrm{J}$ Obstet Gynaecol 104(5):601-607

90. Jorgensen JCV, Pelle J, Philipsen T (1996) Fatal infection following transvaginal fibroid resection. Gynaecol Endoscopy 5 (4):245-246

91. Wood C, Maher P (1998) Endoscopic treatment of uterine fibroids. Baillieres Clin Obstet Gynaecol 12(2):289-316

92. Thurkow AL. NVOG Modelprotocol nr. 5: Submukeuze myomen, diagnostiek en therapie. NVOG, 20 September 2006. NVOG (report) 